\title{
Study on Application of Microlecture in College Music Teaching
}

\author{
Lu Wang \\ Anshan Normal University \\ Liaoning, China
}

\begin{abstract}
With the rapid development of information technology, microlecture, as a new teaching resource, has been widely applied in college courses teaching and thus promoted the innovation of teaching. As an artistic subject, music bears its unique characteristics, which make it different from other disciplines. The application of microlecture in college music teaching is of great significance in enhancing students' learning interest, creating efficient classes and improving teaching effectiveness and quality. At present, what concerns the music teachers most centers on how to make better use of the role of microlecture in music teaching, to analyze the characteristics of students and the nature of curriculum, and to explore the better application of microlecture in teaching. This paper mainly discusses the effective application of microlecture in college music teaching.
\end{abstract}

Keywords-Microlecture; College music; Educational reform; Application

\section{INTRODUCTION}

For students under higher education, music course learning not only requires them to master professional knowledge of music, but also needs them to comprehend the charm and soul of the art of music. Since the personalities and values have been formed on the group of college students, traditional teaching can no longer fit in with the characteristics of students in this age, for it is difficult to stimulate students' learning interest and improve teaching efficiency. In view of the current traditional teaching model of colleges and universities, educators are gradually carrying out teaching reforms and innovating teaching methods to be adapted to students' characteristics. As a new type of teaching method based on micro-video, microlecture has broken through the limitation of time and space, and enriched the teaching methods by its catching sound effects, images and many other features. Due to the emphasis on practicality of art of music, microlecturing has become an important teaching method by reinforcing students' understanding of the work. How to make microlecture effectively used in music teaching in colleges and universities becomes one of the important research topics of current educators, and meanwhile is the focus of this article.

\section{WhAT IS MiCROLECTURE}

With video as the main carrier, microlecture, as a kind of miniature course, records the entire process of teaching around a certain knowledge point or teaching program by using the information technology in classroom teaching [1]. Video is the core of microlecture. It is a teaching aid resource focusing on a series of teaching activities around the teaching subjects, such as teaching design, material selection, teaching reflection, association test, student feedback, and teacher commenting, to create a small classroom environment. Microlecture is a new type of teaching resource inherited and developed on the basis of traditional teaching resources, including teaching cases, courseware, design, reflection, etc

Compared with traditional curriculum teaching, microlecture is mainly characterized as follows: The curriculum time is short. Generally, the duration of microlecture is 5-8 minutes, or no more than 10 minutes; The content is more concise. Since the microlecture is a teaching activity based on the key points and difficult points in the curriculum, it is targeted with a highlighted theme and less content than the traditional course; Resource capacity is small. Microlecture is suitable for mobile learning; Teaching design is more sophisticated. In microlecture, the teaching cases are typical, authentic and specific; Results are simplified. It is easy to transform, with various forms of dissemination; Feedback is timely. Microlecture is conducive to students' self-learning [2]. 


\section{THE IMPORTANCE OF MiCROLECTURE IN MUSIC TEACHING}

\section{A. To Improve Students' Interest in Music Learning}

In music course learning, interest is particularly important. Students can take initiative to study only when they are interested in what they are learning. As thus, the efficiency of classroom teaching can be improved and students' subjectivity can be fully exerted. Through microlecture, students can select appropriate content based on their own needs, or make out a study plan according to the learning schedule. In terms of this, microlecture has a strong advantage compared with the traditional teaching model where students are required to study the same content under the arrangement of the teacher. In the traditional teaching model, it is necessary to keep consistency in teaching content and progress, which however, can be adjusted by the students in the microlecturing model. This is conducive to the full play of enthusiasm and initiative of the students and helpful for the motivation of students' music learning interest. In addition, the microlecture teaching requires teachers to explore more resources for teaching, to achieve a situational and scene-based teaching, which not only creates a good classroom atmosphere, but also inspires students' interest through more visual and specific teaching. For example, in the study of classical music, with regard to traditional Chinese culture, microlecture can be used to help students comprehend the connotation of traditional culture while enjoying music, so as to enhance their understanding of classical music and improve teaching efficiency. Microlecture can not only stimulate students' interest in music, but also deepen their understanding and comprehension of music.

\section{B. To Enable Students to Grasp New Knowledge More Efficiently}

Music is an art discipline. Creation can be accomplished only when students thoroughly understand art. Different from traditional teaching methods, microlecturing enables students to preview and study without teachers' on-site teaching. The only thing they need is to instruct students and respond to their questions. Relatively speaking, the role of microlecture in the classroom surpasses that of traditional teaching. Although there is no need for teachers to spend more time and efforts on teaching, it may take their more time to prepare lessons and select materials outside the classroom. For the teaching of new knowledge, teachers should collect relevant microlecuture resources or self-produced microlectures in the early stage, focusing on the introduction of knowledge points as well as the explanation of the puzzles and difficulties, which not only saves classroom time, but also creates an efficient classroom, making students quickly master new knowledge. The instruction of teachers will improve students' self-study ability, thus establishing the efficient classes.

\section{To Help Teachers to Enrich Music Teaching Content}

In the traditional music teaching classroom, less music can be provided for students to learn and appreciate. The lack of resources leads to the inadequacy of music teaching content and students' mediocre music appreciation ability. The introduction of microlecture resources, that is, the use of a variety of forms, categories, and ethnic groups of musical works in class, has changed the tedious characteristic of traditional music teaching, and now it is unnecessary for the teacher to teach all the content in class. All they need is to allow students to appreciate and experience from different perspectives by putting emphasis on the important content and adopting different forms to enhance students' aesthetic and appreciation ability. In addition, microlecturing is a new type of teaching implemented through information technology, by means of which teachers can not only find the corresponding microlecture resources on the Internet, but also can use existing resources to make microlecture and develop teaching around the established teaching goals, to provide more comprehensive teaching content for students, enrich their knowledge, and broaden their horizons. As students have more access to new knowledge and musical works in microlectures, their musical skills and appreciation are improved. At the same time, the use of microlecture can help students to develop better study habits, encourage them to study and explore independently, and improve their musical literacy.

\section{THE APPLICATION OF MiCROLECTURE IN MUSIC TEACHING}

\section{A. The Application of Microlecture in the Introduction of New Course}

The introduction of new courses is a crucial part of the entire classroom teaching process, for whether the attention of students can be attracted at the beginning even determines the efficiency of teaching throughout the classroom [3]. As is known, each college student have a strong personality. Therefore, whether an effective form is adopted or not at the beginning of the course determines their performance and learning desire in class. Better introduction can attract and increase their attention at the beginning of the class. In music teaching, music enjoying and language introduction are most commonly used in the introduction of new courses. The former allows students to listen to music and reflect on the work by means of sound. While the latter mainly depends on the teacher to elaborate the information about the work, or small stories related to the composer. Nevertheless, due to the excessive use of these two methods, students began to run out of their curiosity and inquisitive mind. Then the forms of the introduction of new courses are enriched by the emergence of microlectures. For example, the video of "Super Girl Folk Song Medley" can be played to the students while introducing the folk song appreciation teaching. Taking video as the main form, microlecture attracts students to specific context from the perspective of manifestation. It allows students to appreciate the folk songs in a harmonious classroom atmosphere to help them get a deeper understanding of the songs. 


\section{B. The Application of Microlecture in Music Singing Teaching}

Singing teaching is an important part of the music curriculum. Generally speaking, the entire lesson centers around the demonstration of one song to help students to master. Unlike other disciplinary knowledge, songs require students with a strong understanding and practical ability in terms of singing skills, not easy to grasp by just relying on teachers' demonstration and students' repeated practice. In singing teaching, in accordance with teaching objectives, a series of activities such as appreciation, vocalization, model singing and demonstration singing will be developed by teachers. However, they will encounter many problems throughout the entire process, such as frequent unsatisfactory in high pitch demonstration as well as students' singing practice. Of course, it is not hard to imagine that there may be differences between the first and the second demonstration of teachers. But the application of microlecure will remedy the defects existing in traditional teaching by using existing microlecture resources or recording small videos as teaching materials for students to imitate and learn. This can stimulate students' interest in classroom learning, arouse their enthusiasm and mobilize their initiative, enrich the teaching resources and realize the student's subjectivity, to transform teachers' repeated demonstration and students' repeated practice in traditional teaching. In the effective application of microlectures in music singing teaching, students are enabled to experience singing on their own, thus simplifying the teaching difficulties.

\section{The Application of Microlecture in Classroom Musical Instrument Performance}

Musical instruments are a kind of carrier to show the soul of music. Through instrumental performance, players' understanding of music and their perception of the works can be manifested, in addition to their creativity. Therefore, musical instrument playing becomes an important part of the music course learning, which reinforce the musical expressiveness, improves the overall quality of students and promote their all-round development. Since each kind of musical instrument expresses music in a different way, it is difficult for teachers in the traditional classroom to present a variety of performance methods for students to observe and compare. While in microlecturing, various musical instrument performance methods are presented through the forms of sound, video, and text to allow students to experience the artistic charm and soul of the music and deepen their understanding of music. Furthermore, microlectures are more intuitive and visual by means of the presentation of video, helping students to get a deeper understanding of various playing styles. For example, while choosing microlecture resources, teachers can focus on those curriculum resources that can improve students' abilities and then thoughtfully design the microlecture to allow students to concretely feel the way that music is played, helpful for the improvement of classroom teaching efficiency.

\section{The Application of Microlecture in Music Rhythm Training}

Rhythm is like the bone of music, closely related to melody. It is the fundamental element of music, also the key to learning singing. Rhythm training, tedious in the entire process of music learning, needs repeated practice. It is pretty hard for the students to achieve ideal results, even if much time has been spent on training. This is mainly because rhythm training is dull and boring. It always leads to low efficiency in learning if students are only demanded to mechanically practice in a repeated manner without being instructed to learn and practice in an innovative way, or less importance has been attached by teachers to the teaching methods. Since students have their unique characteristics, their ability to grasp the rhythm may vary to some extent. For those who are not able to grasp the rhythm in singing, teachers are required to present the song rhythm and encourage them to practice alone until they can master the rhythm in accuracy. The effect can be imagined if boring practice is over emphasized. While, the application of microlecture has better solved this problem. By using graphic texts and sounds in microlecture, the abstract concept of rhythm is presented more intuitively to students, who then are guided to master the difficulties. This not only mobilizes students' enthusiasm, but also helps them to cultivate selfconfidence.

\section{E. The Application of Microlecture in Music Appreciation Teaching}

Music appreciation course is much important to improve students' emotions and music literacy, which enables students to perceive music in a more vivid way, and improves their appreciation, expressiveness, and creativity. Besides, it plays an important role in cultivating students' aesthetics and enabling them to comprehend the quintessence of art of music. The traditional music appreciation class has been also constantly innovated by applying multimedia tools and methods to classroom teaching. However, the entire teaching process is performed around a piece of music. The teaching resources that can be used in multimedia teaching also have certain limitations. By the application of microlecture, students' curiosity and inquiry psychology can easily be inspired, with teaching materials being presented in video by means of image texts and sound effects. Now that microlectures are mainly characterized by a short duration, in the appreciation class, different performance versions of a piece of music can be put in the classroom for students to learn by taking different forms of microlectures. The form of microlecture can help students develop their subjectivity, making them no longer accept knowledge in a passive way. Works can be appreciated from the perspectives of melody, beats, and rhythm of the work, thus realizing the true purpose of the music appreciation class and achieving the set targets of teaching. For example, in music appreciation class, teachers can analyze a certain work from various perspectives and set a corresponding scene in the classroom so that students are able to integrate into the situation and feel the expressiveness of the music more easily, thereby improving the effect of classroom teaching. 


\section{CONCLUSION}

Nowadays, microlectures have been widely used in music teaching in colleges and universities due to their characteristics of short duration, small size, and accessibility in mobile learning. For students, the application of microlecture can stimulate their learning interest, mobilize their initiative for learning, help them to develop a good habit of independent study, and expand their scope of knowledge. For teachers, by means of microlecture resources, they can create teaching situations around teaching content, reform traditional teaching methods, split teaching difficulties, and establish efficient classes. Therefore, the application of microlecture in music classes has greatly improved the quality of teaching. This article mainly discusses the application of microlecture in the introduction of new courses, singing teaching, musical instrument performance, rhythm training, and appreciation teaching, in hope of providing reference for educators through the viewpoints in the article.

\section{REFERENCES}

[1] Musical Specialty of Higher Education [J]. Western China Quality Education, 2017, (9).

[2] Lin Feng, Wu Ronghua. Reflections on Forms and Value Identification of Microlectures in Music Teaching [J]. Art Review, 2017, (16).

[3] Lan Xia. Effective Development and Application of Microlectures in Music Teaching [J]. Chinese Music Education, 2017, (12). 